\title{
Suppressors of a U4 snRNA mutation define a novel U6 snRNP protein with RNA-binding motifs
}

\author{
Karen W. Shannon and Christine Guthrie \\ Department of Biochemistry and Biophysics, University of California, San Francisco, California 94143 USA
}

\begin{abstract}
U4 and U6 small nuclear RNAs are associated by an extensive base-pairing interaction that must be disrupted and reformed with each round of splicing. U4 mutations within the U4/U6 interaction domain destabilize the complex in vitro and cause a cold-sensitive phenotype in vivo. Restabilization of the U4/U6 helix by dominant (gain-of-function), compensatory mutations in U6 results in wild-type growth. Cold-insensitive growth can also be restored by two classes of recessive (loss-of-function) suppressors: (1) mutations in PRP24, which we show to be a U6-specific binding protein of the RNP-consensus family; and (2) mutations in U6, which lie outside the interaction domain and identify putative PRP24-binding sites. Destabilization of the U4/U6 helix causes the accumulation of a PRP24/U4/U6 complex, which is undetectable in wild-type cells. The loss-of-function suppressor mutations inhibit the binding of PRP24 to U6, and thus presumably promote the release of PRP24 from the PRP24/U4/U6 complex and the reformation of the base-paired U4/U6 snRNP. We propose that the PRP24/U4/U6 complex is normally a highly transient intermediate in the spliceosome cycle and that PRP24 promotes the reannealing of U6 with U4.
\end{abstract}

[Key Words: Saccharomyces cerevisiae; splicing; snRNP; U6 snRNA; PRP24; RNP motif]

Received January 18, 1991; revised version accepted February 28, 1991.

The removal of intervening sequences from pre-mRNA occurs in a large complex called the spliceosome. Essential components of the spliceosome include five evolutionarily conserved small nuclear RNAs (snRNAs), U1, U2, U4, U5, and U6 (for review, see Sharp 1987; Guthrie and Patterson 1988|. U1, U2, and U5 are found in separate small ribonucleoprotein particles (snRNPs), each containing a set of common proteins (known as Sm proteins) and a number of snRNP-specific proteins (for review, see Lührmann 1988). In contrast, U4 and U6 are found base-paired together within a single particle (Bringmann et al. 1984; Hashimoto and Steitz 1984).

The formation of the spliceosome is a highly ordered process that involves the stepwise assembly of the snRNPs onto the pre-mRNA. Following binding of U1 and U2 snRNPs to the $5^{\prime}$ splice site and branchpoint regions, respectively (Mount et al. 1983; Black et al. 1985), the U4/U6 snRNP is incorporated into the spliceosome, probably in association with the U5 snRNP (Pikielny et al. 1986; Bindereif and Green 1987; Cheng and Abelson 1987; Konarska and Sharp 1987). Subsequently, the U4/ U6 snRNP undergoes a dramatic conformational change, such that $\mathrm{U} 4$ is no longer associated with the spliceosome upon electrophoresis in nondenaturing conditions (Pikielny et al. 1986; Cheng and Abelson 1987; Lamond et al. 1988). This conformational rearrangement is accompanied by the appearance of splicing intermediates and products. The temporal correlation between these events suggests that destabilization of the U4/U6 interaction may be involved in the catalytic activation of the spliceosome (Brow and Guthrie 1989). Once splicing has occurred, the U4/U6 interaction must presumably be reformed prior to the next round of splicing. Thus, the spliceosome cycle appears to involve the dynamic interconversion between the base-paired and the destabilized forms of the U4/U6 snRNP.

It has been proposed on phylogenetic grounds (Brow and Guthrie 1988) that U4 and U6 interact via base-pairing to form two intermolecular helices (stem I and stem II), which are separated by an intramolecular stem in U4 (see Fig. 1, below). The existence of stem I has been established by psoralen cross-linking experiments (Rinke et al. 1985). In vitro reconstitution studies have shown that both stem I and stem II are required for the formation of the U4/U6 snRNP (Hamm and Mattaj 1989; Pikielny et al. 1989; Bindereif et al. 1990; Vankan et al. 1990). The extensive base-pairing interaction between $\mathrm{U} 4$ and $\mathrm{U} 6$ is consistent with the observation that the U4/U6 snRNP is very stable in vitro $\left(T_{\mathrm{m}} \sim 53^{\circ} \mathrm{C}\right.$ ) (Brow and Guthrie 1988); this has prompted speculation that an ATP-dependent RNA helicase may mediate the unwinding event. Because the U4/U6 helix is energetically favorable compared to the unwound state, an RNA-binding protein may additionally be required to stabilize $\mathrm{U} 4$ and/or U6. Finally, in that the reformation of hydrogen bonds between the complementary bases in $\mathrm{U} 4$ and $\mathrm{U} 6$ 
requires the two RNAs to be closely and specifically aligned, the reannealing event may also be an active process. However, there is as yet little information about the role of such putative factors in splicing.

Here, we describe a genetic approach to identify transacting factors required for the destabilization and/or restabilization of the U4/U6 complex during the spliceosome cycle. Our strategy involved (1) the generation of mutations in U4 that destabilize the U4/U6 complex in vitro and cause conditional lethal phenotypes in vivo, and (2) the isolation of extragenic suppressor mutations that restore wild-type growth. This has led us to identify a new member of the RNP-consensus family of RNAbinding proteins (Bandziulis et al. 1989; Query et al. 1989|, PRP24. We show that PRP24 is a novel U6snRNP protein and that the growth defect resulting from the destabilization of $\mathrm{U} 4 / \mathrm{U} 6$ is suppressed by mutations in the RNP-consensus motifs of PRP24 and by mutations in putative-binding sites for this protein in U6. The genetic and biochemical properties of these mutants suggest that PRP24, shown previously to be an essential splicing factor (Vijayraghavan et al. 1989), mediates the reformation of the U4/U6 snRNP. Another member of the RNP-consensus family, hnRNP Al, has recently been reported to promote RNA annealing in vitro (Pontius and Berg 1990).

\section{Results \\ U4 mutations that destabilize the U4/U6 interaction cause a cold-sensitive phenotype}

In initial experiments we used a genetic approach to identify nucleotides required for the stability of the U4/ $\mathrm{U} 6$ complex in vivo. In yeast, $\mathrm{U} 4$ and $\mathrm{U} 6$ are encoded by single-copy genes that are essential for growth (Siliciano et al. 1987; Brow and Guthrie 1988). We used site-directed mutagenesis to make each of the single-base changes in U4 at positions 14,13,10, and 9 from the $5^{\prime}$ end of U4 (Fig. 1). The mutations were introduced into a strain carrying a deletion of the gene encoding U4 (SNR14) using the plasmid shuffle technique (Boeke et al. 1987). Strains containing both wild-type and mutant U4 alleles showed no growth defect, indicating that the mutations are recessive (data not shown). However, most of the strains containing only the mutant alleles showed a cold-sensitive phenotype (Table 1). The snr14G14C mutant, which contains a G $\rightarrow C$ change at position 14, had the most dramatic cold-sensitive phenotype; it failed to grow at $18^{\circ} \mathrm{C}, 22^{\circ} \mathrm{C}$, or $25^{\circ} \mathrm{C}$ but grew well at $30^{\circ} \mathrm{C}$ and $37^{\circ} \mathrm{C}$. The secondary structure model predicts that this mutation would disrupt a stack of three $\mathrm{G}: \mathrm{C}$ base pairs between U4 and U6. The snr14-C10T mutant, which contains the $\mathrm{C} \rightarrow \mathrm{T}$ change at position 10 , was the

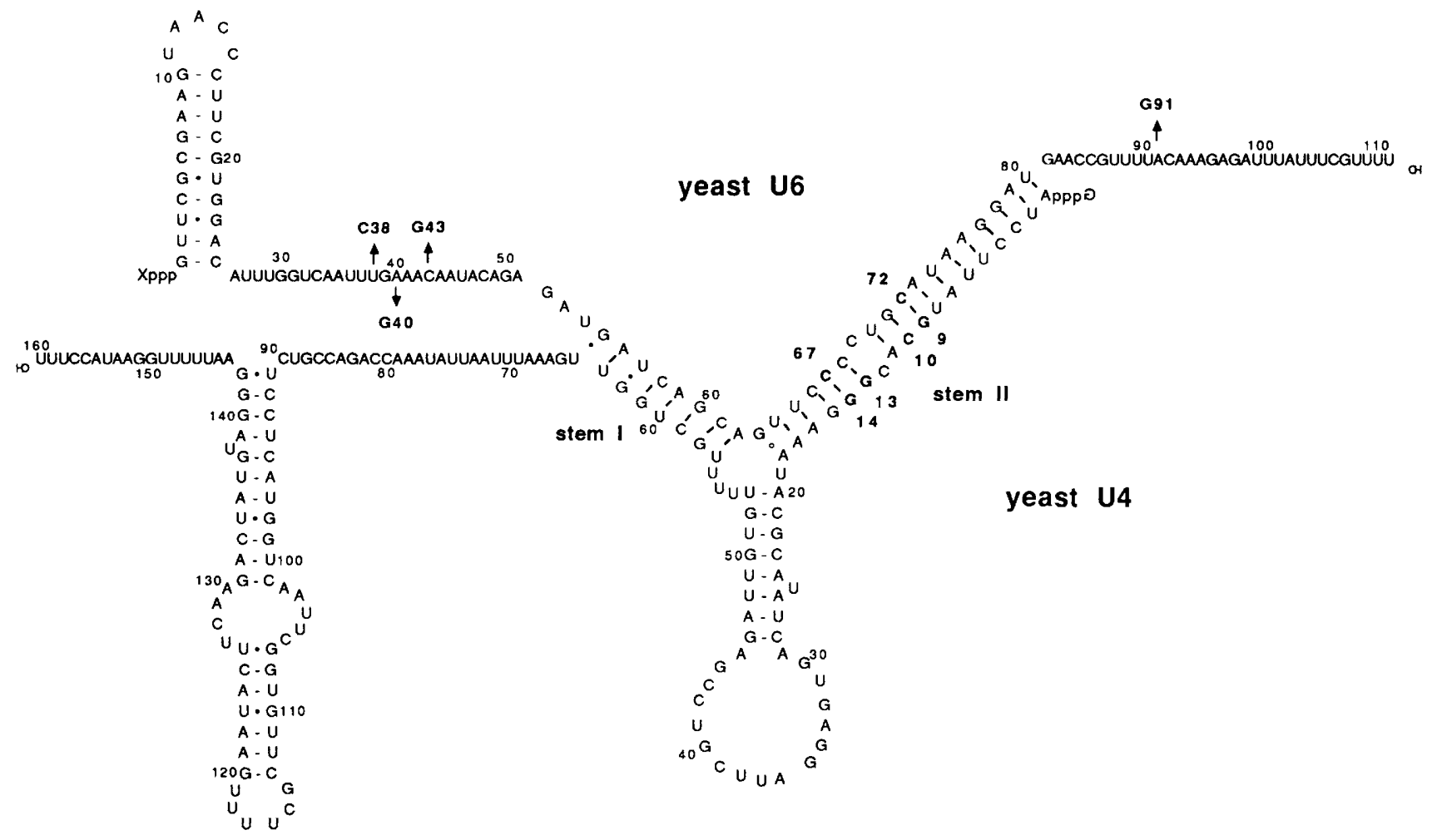

Figure 1. Secondary structure of the yeast U4/U6 complex, as proposed by Brow and Guthrie (1988). The position of the snr14 and snr6 mutations generated by site-directed mutagenesis are indicated in boldface type. The position and sequence of the spontaneous recessive suppressor mutations in $\mathrm{U} 6$ are indicated with arrows. 
Table 1. Phenotype of snrl4 mutants

\begin{tabular}{lccccc}
\hline & \multicolumn{5}{c}{ Temperature $\left({ }^{\circ} \mathrm{C}\right)$} \\
\cline { 2 - 6 } snr14 strain & 18 & 22 & 25 & 30 & 37 \\
\hline Wild-type & + & + & + & + & + \\
G14A & - & + & + & + & + \\
G14C & - & - & - & + & + \\
G14T & - & - & + & + & + \\
G13A & - & + & + & + & + \\
G13C & - & + & + & + & + \\
G13T & - & + & + & + & + \\
C10A & - & + & + & + & + \\
C10G & - & + & + & + & + \\
C10T & + & + & + & + & + \\
G9A & - & + & + & + & + \\
G9C & - & + & + & + & + \\
G9T & - & + & + & + & + \\
\hline
\end{tabular}

only mutant strain of the 12 tested that did not show a cold-sensitive phenotype. This mutation would allow the formation a $G: U$ base pair, which would presumably maintain a stable U4/U6 interaction.

To test whether these mutations in fact destabilize the U4/U6 complex, we prepared snRNP-enriched fractions from several mutant strains and determined the $T_{m}$ (temperature at which $50 \%$ dissociation is observed) of the U4/U6 complex in these fractions after treatment with proteinase-K and SDS (Fig. 2). The $T_{\mathrm{m}}$ of the U4/U6 complex in the snr $14-C 10 T$ strain was $\sim 51^{\circ} \mathrm{C}$, which is similar to the $T_{\mathrm{m}}$ of $\sim 53^{\circ} \mathrm{C}$ measured in wild-type strains (Brow and Guthrie 1988). The $T_{m}$ of U4/U6 in the snr14G14C strain was $\sim 37^{\circ} \mathrm{C}$, indicating that the U4/U6 complex is significantly less stable in this mutant. These data may suggest that destabilizing the U4/U6 complex causes the cold-sensitive phenotype observed in vivo.

To provide more direct evidence for this hypothesis, we used the strategy of making compensatory base-pair changes. Using site-directed mutagenesis, we made each single-base change in U6 at positions 67 and 72; positions 67 and 72 of U6 are predicted to base-pair with positions 14 and 9 of $U 4$, respectively (Fig. 1). We introduced the U6 mutant alleles into strains containing the U4 mutations and looked for suppression of the coldsensitive phenotype (Fig. 3). Each of these strains also contained a wild-type copy of the gene encoding U6 (SNR6). Strains carrying mutant U6 alleles in combination with wild-type U4 alleles showed no growth defect, indicating that the U6 mutations did not have a dominant negative effect. Transforming the U4 mutant strains with the wild-type U6 allele or the predicted noncompensatory U6 alleles did not alleviate the cold-sensitive growth defect. However, when we restored the potential for base-pairing between $\mathrm{U} 4$ and $\mathrm{U} 6$ by introducing the compensatory U6 alleles, wild-type growth was restored. These results demonstrate that U4 (positions 14 and 9) and U6 (positions 67 and 72, respectively) interact via Watson-Crick base-pairing. Moreover, these results argue that the cold-sensitive phenotype is due to the disruption of base-pairing between U4/U6.
Two classes of mutations in U6 suppress the cold-sensitive phenotype of the snr14-G14C mutation

The finding that mutations that destabilize the U4/U6 base-pairing interaction cause a cold-sensitive phenotype was unexpected, because cold sensitivity is generally thought to reflect the hyperstabilization of a complex. One possible explanation is that the U4/U6 complex is in equilibrium with an alternative, competing complex; mutations that destabilize the U4/U6 complex would drive this equilibrium toward the formation of the alternative complex. If true, we would expect mutations that destabilize the competing complex to suppress the cold-sensitive phenotype of the U4 mutant strains. To pursue this possibility, we isolated five spontaneous independent revertants that grew at $18^{\circ} \mathrm{C}$. Each revertant

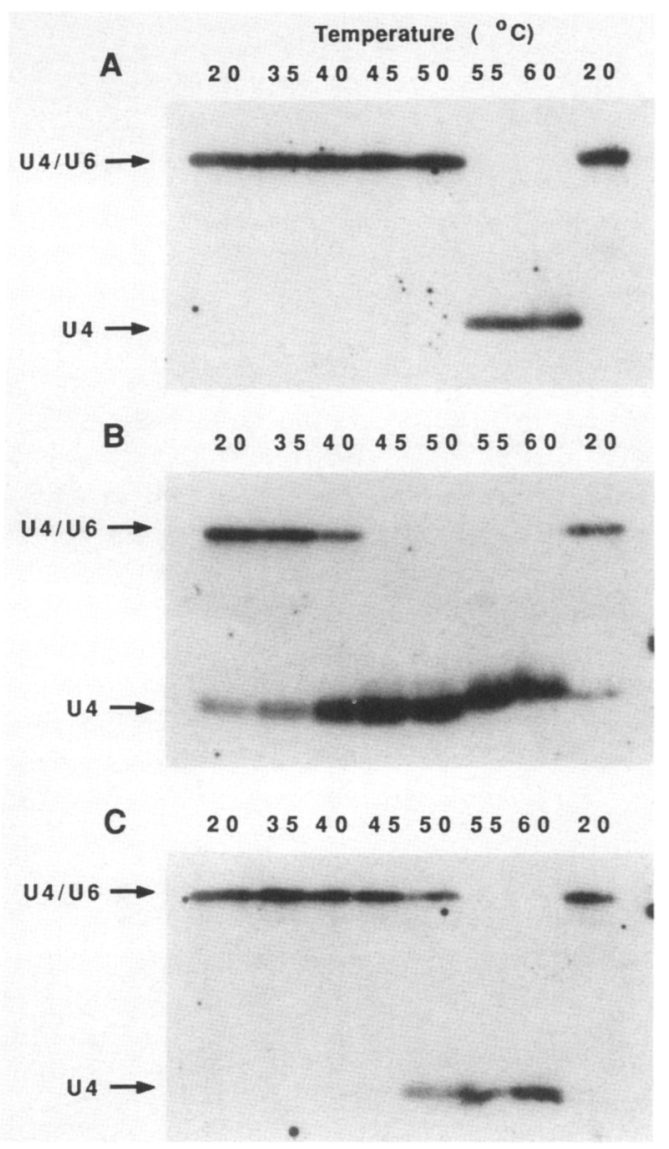

Figure 2. $T_{\mathrm{m}}$ determinations of the U4/U6 complex in $s n r 14$ mutant strains. Aliquots of proteinase-K/SDS-treated fraction I prepared from a wild-type strain (MATa trp1 his 3 ura3 ade2 lys2 snr14::TRP1 pUN90-SNR14) $|A|$, the snr14-G14C strain (MATa trp1 his3 ura3 ade2 lys2 snr14::TRP1 pUN90-snr14 $G 14 C)(B)$, or the snr14-C10T strain (MATa trp1 his3 ura3 ade2 lys2 snr14::TRP1 pUN90-snr14-C1OT) $(C)$ were incubated at the temperatures indicated for $5 \mathrm{~min}$ and then subjected to electrophoresis on a native gel. RNA was transferred to a nylon membrane and probed with a ${ }^{32} \mathrm{P}$-labeled oligonucleotide specific for $\mathrm{U} 4$. The bands corresponding to free $\mathrm{U} 4$ and its complex with $\mathrm{U} 6$ are indicated with arrows. 
Figure 3. Growth of snr14 snr6 double mutants. snr14 mutant strains (MATa trp1 his3 ura3 ade2 lys2 SNR6 snr14::TRP1 pUN90-snr14) were generated as described in Materials and methods. YCp50 plasmids carrying the snr6 mutations were introduced into these strains by transformation Transformants were selected, plated onto SD medium lacking histidine and uracil and incubated at the temperatures indicated. Strains were scored for growth $1+\mid$ or no growth $(-)$.

\begin{tabular}{|c|c|c|c|c|c|c|c|c|c|}
\hline \multicolumn{6}{|c|}{ Temperature $\left({ }^{\circ} \mathrm{C}\right)$} & \multicolumn{4}{|c|}{ Temperature $\left({ }^{\circ} \mathrm{C}\right)$} \\
\hline U4, U6 allele & 18 & 25 & 30 & 37 & U4, U6 allele & 18 & 25 & 30 & 37 \\
\hline SNR14, SNR6 & + & + & + & + & SNR14, SNR6 & + & + & + & + \\
\hline SNR14, snr6-C67A & + & + & + & + & SNR14, snr6-C72A & + & + & + & + \\
\hline SNR14, snr6-C67G & + & + & + & + & SNR14, snr6-C72G & + & + & + & + \\
\hline SNR14, snr6-C67T & + & + & + & + & SNR14, snr6-C72T & + & + & + & + \\
\hline snr14-G14A, SNR6 & - & + & + & + & snr14-G9A, SNR6 & - & + & + & + \\
\hline snr14-G14A, snr6-C67A & - & + & + & + & snr14-G9A, snr6-C72A & - & + & + & + \\
\hline snr14-G14A, snr6-C67G & - & + & + & + & snr14-G9A, snr6-C72G & - & + & + & + \\
\hline snr14-G14A, snr6-C67T & + & + & + & + & snr14-G9A, snr6-C72T & + & + & + & + \\
\hline snr14-G14C, SNR6 & - & $=$ & + & + & snr14-G9C, SNR6 & - & + & + & + \\
\hline snr14-G14C, snr6-C67A & - & - & + & + & snr14-G9C, snr6-C72A & - & + & + & + \\
\hline snr14-G14C, snr6-C67G & + & + & + & + & snr14-G9C, snr6-C72G & + & + & + & + \\
\hline snr14-G14C, snr6-C67T & - & $\cdot$ & + & + & snr14-G9C, snr6-C72T & - & + & + & + \\
\hline snr14-G14T, SNR6 & - & + & + & + & snr14-G9T, SNR6 & - & + & + & + \\
\hline snr14-G14T, snr6-C67A & + & + & + & + & snr14-G9T, snr6-C72A & + & + & + & + \\
\hline snr14-G14T, snr6-C67G & + & + & + & + & snr14-G9T, snr6-C72G & + & + & + & + \\
\hline snr14-G14T, snr6-C67T & - & + & + & + & snr14-G9T, snr6-C72T & - & + & + & + \\
\hline
\end{tabular}

was crossed to a parent strain of the opposite mating type to generate diploid strains homozygous for snr14-G14C and heterozygous for the suppressor alleles. One diploid strain grew at $18^{\circ} \mathrm{C}$, indicating that this suppressor mutation was dominant. Four diploid strains did not grow at $18^{\circ} \mathrm{C}$, indicating that these suppressor mutations were recessive. We expected the compensatory U6 mutation to confer a dominant phenotype since the SNR6-C67G mutation suppressed the snr14-G14C mutation in the presence of wild type U6 (Fig. 3). We partially sequenced U6 from total RNA prepared from the dominant suppressor and found a $\mathrm{C} \rightarrow \mathrm{G}$ change at position 67 . We had shown that this single-base change, when generated by site-directed mutagenesis, is sufficient to confer suppression (Fig. 3).

In an attempt to determine the identity of the recessive suppressors, we first transformed these strains with plasmids carrying wild-type alleles of genes encoding the U snRNAs. When a plasmid carrying SNR6 was introduced into any of the recessive suppressor strains, the cells again became cold-sensitive (data not shown). Plasmids carrying genes encoding $\mathrm{U} 1, \mathrm{U} 2, \mathrm{U} 4$, and $\mathrm{U} 5$ had no effect. These data suggest that the recessive suppressor mutations are alleles of SNR6. We then sequenced either the U6 snRNA or the U6 gene from each of the recessive suppressors. In each case, we identified a single-nucleotide change. Each of these mutations maps outside the U4/U6 interaction domain: Three are found in a short stretch $5^{\prime}$ of the interaction domain (snr6-T38C, snr6$A 40 G$, and snr6-C43G), and one is found $3^{\prime}$ of the interaction domain (snr6-A91G) (Fig. 1).
To determine whether these suppressors act by restabilizing the U4/U6 complex, we determined the $T_{m}$ of the $\mathrm{U} 4 / \mathrm{U} 6$ complex in proteinase-K/SDS-treated fractions prepared from several strains. As expected, the $T_{\mathbf{m}}$ of the U4/U6 complex in the dominant suppressor containing the compensatory change in U6 (SNR6-C67G) was $\sim 53^{\circ} \mathrm{C}$ (Fig. $4 \mathrm{~A}$ ), the same as that measured in the wild-type strain. In contrast, the $T_{\mathrm{m}}$ of the complex in one of the recessive suppressor strains $(\operatorname{snr} 6-A 91 G)$ was $\sim 37^{\circ} \mathrm{C}$ (Fig. $4 \mathrm{~B}$ ), the same as that measured in the snr14$G 14 C$ strain. Thus, it appears there are at least two mechanisms by which mutations in U6 can suppress the snr14-G14C mutation, one of which does not restore wild-type stability to the U4/U6 complex in vitro.

\section{Mutations in PRP24 suppress the cold-sensitive phenotype of the snr14-Gl4C mutation}

The fact that we isolated recessive suppressor mutations in U6 suggested to us that U6 may be involved in an interaction that competes with the U4/U6 base-pairing interaction. If true, we would expect to recover additional recessive suppressor mutations in genes encoding factors that are associated with U6. Thus, we attempted to isolate suppressors by a second strategy, in which we selected against recessive suppressors in the U6 gene. To accomplish this, an additional copy of the wild-type U6 gene was introduced into the snr14-G14C strain by transformation with a plasmid carrying SNR6 and $U R A 3$. We plated these cells at $18^{\circ} \mathrm{C}$ and picked revertants. Cells that lost the URA3-marked plasmid were 


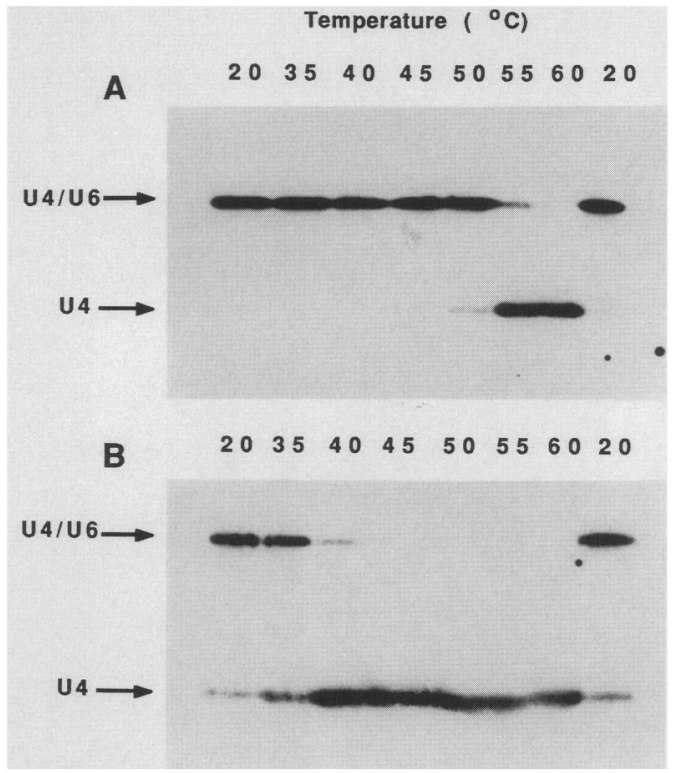

Figure 4. $T_{\mathrm{m}}$ determinations of the U4/U6 complex in suppressor strains. Aliquots of proteinase-K/SDS-treated fraction I prepared from the suppressor containing the SNR6-C67G mutation (MATa trp1 his3 ura3 ade2 lys2 snr14::TRP1 pUN90snr14-G14C SNR6-C67G) (A) or the snr6-A91G mutation (MATa trp1 his3 ura3 ade2 lys2 snr14::TRP1 pUN90-snr14$G 14 C$ snr6-A91G) $(B)$ were incubated at the temperatures indicated for $5 \mathrm{~min}$. The samples were analyzed by native gel electrophoresis as described in the legend to Fig. 2. The bands corresponding to free U4 and the U4/U6 complex are indicated.

then selected by plating the cells on 5-fluoro-orotic acid (5-FOA). Cells that could not grow at $18^{\circ} \mathrm{C}$ on 5-FOA presumably contain a dominant suppressor mutation in a gene carried by the plasmid and were discarded. Using this scheme, we recovered 14 independent revertants. Each revertant was crossed to a parent strain of the opposite mating type to generate diploids homozygous for the snr14-G14C allele and heterozygous for the suppressor allele. These diploids were tested for their ability to grow at $18^{\circ} \mathrm{C}$. Diploid strains generated from 11 of the revertants did grow at $18^{\circ} \mathrm{C}$, indicating that these suppressor mutations were either dominant or intragenic revertants. Diploid strains generated from three of the suppressors did not grow at $18^{\circ} \mathrm{C}$, indicating that these mutations were recessive. Only the recessive revertants were considered further.

Two of the recessive revertants grew at all temperatures tested. The third recessive revertant showed a recessive temperature-sensitive growth defect; these haploid cells grew at $18^{\circ} \mathrm{C}$ and $25^{\circ} \mathrm{C}$ but failed to grow at $30^{\circ} \mathrm{C}$ and $37^{\circ} \mathrm{C}$. The diploid strains generated from the recessive revertants were sporulated. In each case, tetrad analysis showed that the cold-resistant phenotype segregated $2: 2$, indicating that each suppressor is caused by a mutation in a single nuclear gene. Tetrad analysis of the diploid strain generated from the temperature-sensitive revertant showed that the suppressor phenotype coseg- regated with the temperature-sensitive growth defect, indicating that a single mutation caused both phenotypes. Standard complementation and allelism tests showed that all three suppressors were due to mutations in the same gene.

In an attempt to identify the suppressor gene, we took advantage of the temperature-sensitive suppressor allele and performed complementation analysis with a set of temperature-sensitive mutants defective in pre-mRNA splicing (Hartwell 1967; Vijayraghavan et al. 1989). This analysis demonstrated that the suppressors were mutations in PRP24. The prp24-1 allele was originally identified as a temperature-sensitive mutation that accumulates pre-mRNA at the nonpermissive temperature (Vijayraghavan et al. 1989). We cloned the wild-type PRP24 gene on the basis of its ability to complement the temperature-sensitive growth defect of the U4 suppressor. This temperature-sensitive strain was transformed with a yeast genomic library constructed in a centromere plasmid (Rose 1987) and plated on selective medium at $37^{\circ} \mathrm{C}$. Two related plasmids containing $19-$ to $20-\mathrm{kb}$ inserts were recovered. We isolated a $3.5-\mathrm{kb} X \mathrm{XaI}$ fragment that conferred temperature resistance. We partially sequenced this clone and found an open reading frame that contained sequence motifs conserved among RNA-binding proteins of the RNP-consensus family (Fig. 5) (Bandziulis et al. 1989; Query et al. 1989). Mahshid Company and John Abelson have independently cloned and sequenced this $3.5-\mathrm{kb}$ genomic fragment and found a single open reading frame that can encode a $51-\mathrm{kD}$ protein (pers. comm.). We examined this sequence and found that PRP24 contains three tandem regions homologous to the $\sim 80$ amino acid RNP-consensus domain.

\section{Changes in the RNP-consensus domain of PRP24 are necessary for suppression}

As a first step toward understanding how prp24 mutations act to suppress the snr14-G14C mutation, we cloned and partially sequenced the prp 24 gene from each of the suppressors containing the prp24 alleles. We used the gap repair method (Orr-Weaver et al. 1981) to isolate the mutant prp24 genes. A yeast centromere plasmid carrying the wild-type $P R P 24$ gene was linearized at an internal ClaI site and introduced into each of the three suppressors. Transformants were selected and screened for their ability to grow at $18^{\circ} \mathrm{C}$. Approximately $80 \%$ of the transformants grew at $18^{\circ} \mathrm{C}$, suggesting that the plasmid-linked allele of $P R P 24$ was efficiently repaired to the mutant allele. In each case, we recovered the plasmids from three independent $18^{\circ} \mathrm{C}^{+}$transformants and sequenced $\sim 275$ nucleotides on either side of the ClaI site. We compared these sequences to the wild-type PRP24 sequence and found single nucleotide changes in regions corresponding to highly conserved elements within the carboxy-terminal RNP-consensus domain (Fig. 5). Two of the suppressors (prp24-2 and prp24-3) contained a mutation in the conserved element, called RNP 1. This 8amino-acid motif is the region of highest conservation within the $\sim 80$-amino-acid RNP-consensus domain 
Shannon and Guthrie

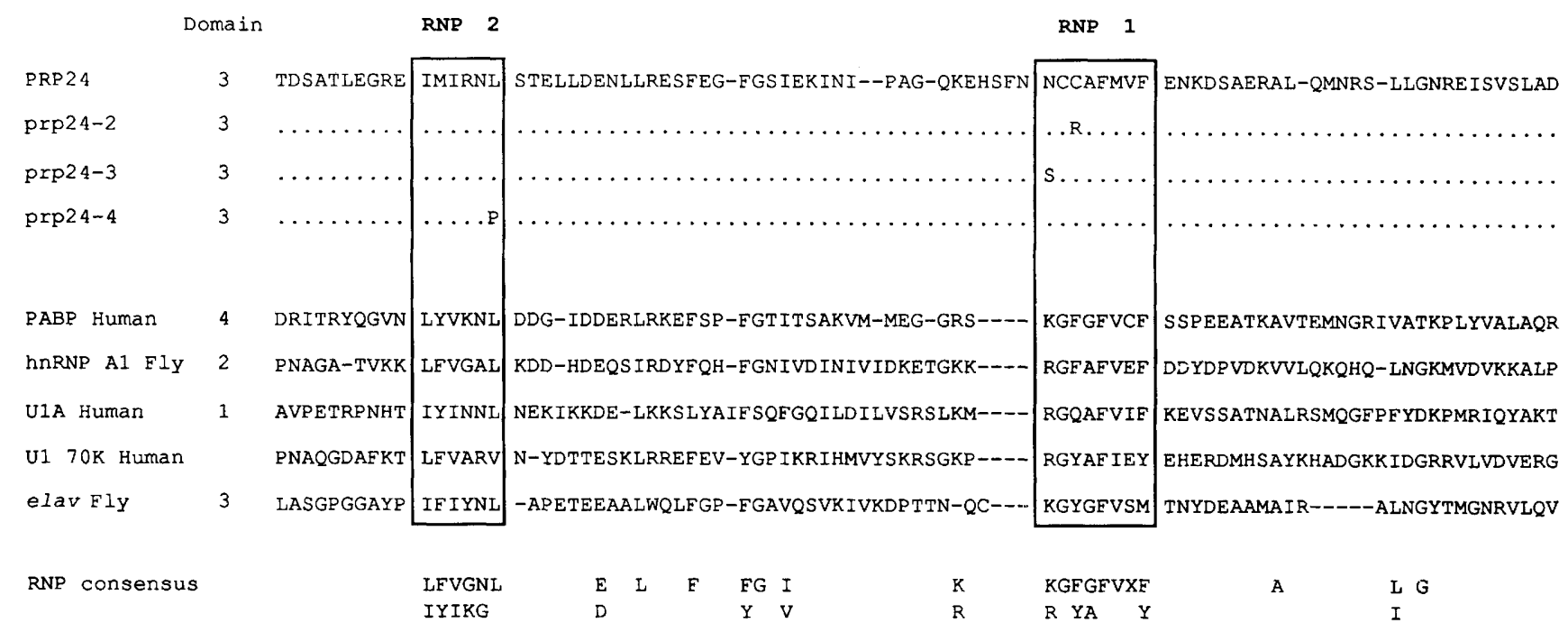

Figure 5. Sequence of PRP24 in suppressor strains. Amino acid sequences of PRP24 (amino acids 202-288) in a wild-type strain and the suppressor strains containing the prp24-2, prp24-3, and prp24-4 mutations are aligned with sequences containing the RNPconsensus domain: human polyadenylate-binding protein (PABP) domain 4 (Grange et al. 1987), Drosophila hnRNP Al domain 2 (Haynes et al. 1987), human U1 A (Sillekens et al. 1987), human U1 70K (Theissen et al. 1986), and Drosophila elav domain 3 (Robinow et al. 1988). Residues of PRP24 from the suppressor strains that are identical to PRP24 from the wild-type strain are indicated by dots. Gaps introduced to maximize homology are marked by hyphens. Sequence elements RNP 2 and RNP 1 are boxed. RNP-consensus sequences were identified previously by Bandziulis et al. (1989).

(Bandziulis et al. 1989). The temperature-sensitive suppressor (prp24-4) contains a mutation in a region called RNP 2 that changes a highly conserved leucine residue to a proline. Previous work has shown that mutations in RNP 2 or RNP 1 block the binding of the snRNP protein U1A to U1 snRNA in vitro (Scherly et al. 1989).

\section{U6 snRNA coimmunoprecipitates with the PRP24 protein in wild-type extracts}

The genetic analysis demonstrates that mutations that destabilize the U4/U6 complex can be suppressed by single-nucleotide changes in U6 and single-amino-acid changes in regions of PRP24 that correspond to putative RNA-binding sites. A parsimonious explanation for these observations is that the U4/U6 complex is in equilibrium with a complex containing PRP24 and U6. To test this prediction directly we generated antibodies to PRP24. We used the cloned PRP24 gene to construct a trpE/PRP24 fusion, which contained $\sim 85 \%$ of the PRP24 open reading frame. This gene fusion was expressed in Escherichia coli, and the fusion protein was gel-purified from insoluble fractions of $E$. coli lysate. The purified fusion protein was used to immunize rabbits to generate polyclonal antiserum. We cannot detect PRP24 in yeast splicing extracts by Western blot analysis; however, the anti-PRP24 antiserum recognized an $\sim 45-\mathrm{kD}$ protein in extracts prepared from strains that overexpress PRP24 under the control of the glucose-6-phosphate dehydrogenase promoter (Schena et al. 1991) (data not shown). This is not inconsistent with the molecular mass of $51 \mathrm{kD}$ predicted from the nucleotide sequence of PRP24.

We immunoprecipitated PRP24 from splicing extracts prepared from the wild-type strain at various ionic strengths. Coprecipitated RNA species were visualized by Northern blot analysis using labeled oligonucleotide probes (Fig. 6A). Anti-PRP24 antiserum immunoprecipitated $\mathrm{U} 6$ at salt concentrations up to $2.0 \mathrm{M}$, the highest salt concentration tested. Antibodies affinity-purified using the trpE/PRP24 fusion protein also immunoprecipitated U6 (data not shown). U1, U2 (data not shown), U4, and the two forms of yeast U5 were not detectably immunoprecipitated at salt concentrations above $250 \mathrm{~mm}$. Under the less stringent conditions (100 and $250 \mathrm{~mm}$ ), immunoprecipitation of snRNAs was not dependent on the addition of anti-PRP24 antiserum (data not shown). We reproducibly found that the immunoprecipitability of $U 6$ increased with increasing salt concentrations up to $750 \mathrm{~mm}$. Although this observation may be unexpected, it is not unprecedented; the binding of several hnRNP proteins to poly $(\mathrm{G})$ or poly $(\mathrm{U})$ is more efficient at $0.5 \mathrm{M}$ salt than at $0.1 \mathrm{M} \mathrm{NaCl}$ (Swanson and Dreyfuss 1988). The higher salt concentrations may expose epitopes on PRP24 that are masked at lower ionic strengths. The addition of ATP to the splicing extract prior to addition of anti-PRP24 antiserum did not affect the amount of U6 immunoprecipitated nor change the pattern of snRNAs immunoprecipitated (data not shown).

We also immunoprecipitated PRP24 from splicing extracts prepared from various mutant strains (Fig. 6B). Surprisingly, anti-PRP24 antiserum immunoprecipitated both $\mathrm{U} 4$ and $\mathrm{U} 6$ from extracts prepared from the strain containing the snr14-G14C mutation (lane 2). The association of PRP24 with U4 and U6 in this mutant extract was stable at salt concentrations up to at least $2.0 \mathrm{M}$. In contrast, only U6 was immunoprecipitated with anti- 


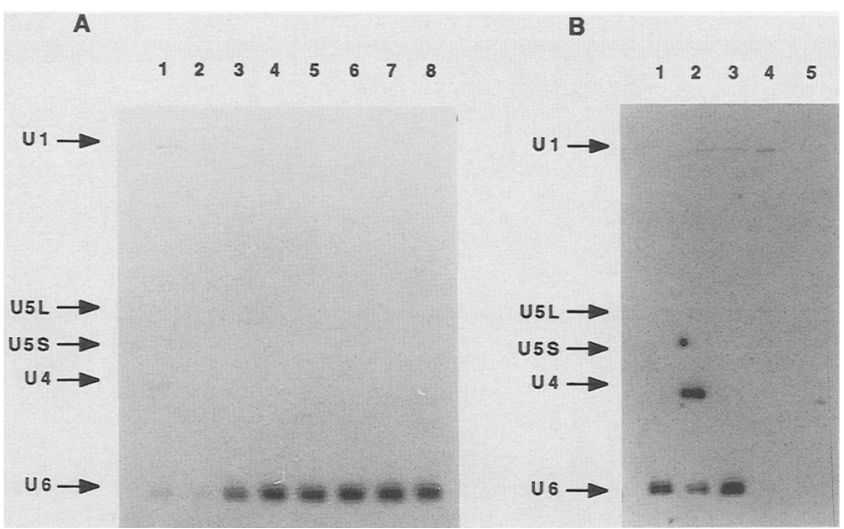

Figure 6. Precipitation of snRNAs with anti-PRP24 antiserum. (A) Splicing extract prepared from a wild-type strain (MATa trp1 his3 ura3 ade2 lys2 snr14::TRP1 pUN90-SNR14) was incubated with anti-PRP24 antiserum at $100 \mathrm{~mm}$ (lane 1), $250 \mathrm{~mm}$ (lane 2), $500 \mathrm{~mm}$ (lane 3), $750 \mathrm{~mm}$ (lane 4), $1.00 \mathrm{M}$ (lane 5), 1.25 $\mathrm{M}$ (lane 6), $1.50 \mathrm{M}$ (lane 7), or $2.00 \mathrm{M}$ (lane 8) NaCl. RNA recovered from the immune complexes was electrophoresed on a $6 \%$ polyacrylamide denaturing gel, transferred to a nylon membrane, and probed with ${ }^{32} \mathrm{P}$-labeled oligonucleotides specific for U1, U4, U5, and U6. The positions of the bands corresponding to $\mathrm{U} 1, \mathrm{U} 4, \mathrm{U} 5$, and $\mathrm{U} 6$ are indicated with arrows. (B) Splicing extract prepared from a wild-type strain (MATa trp1 his3 ura3 ade2 lys2 snr14::TRP1 pUN90-SNR14) (lane 1), the snr14G14C mutant (MATa trp1 his3 ura3 ade2 lys2 snr14::TRP1 pUN90-snr14-G14C) (lane 2), the suppressor strain carrying the SNR6-C67G mutation (MATa trp1 his3 ura3 ade2 lys2 snr14::TRP1 pUN90-snr14-G14C SNR6-C67G) (lane 3), the snr6-A91G mutation (MATa trp1 his3 ura3 ade2 lys2 snr14::TRP1 pUN90-snr14-G14C snr6-A91G) (lane 4) or the prp24-2 mutation (MATa trp1 his3 ura3 ade2 lys2 snr14::TRP1 pUN90-snr14-G14C prp24-2) (lane 5) was incubated with antiPRP24 antiserum at $2.0 \mathrm{M} \mathrm{NaCl}$. RNA recovered from the immune complexes was treated as in $A$.

PRP24 antiserum in extracts prepared from the dominant suppressor SNR6-C67G (lane 3). Thus, it appears that U4 coimmunoprecipitates with PRP24 only when the U4/U6 base-pairing interaction is disrupted. AntiPRP24 antiserum precipitated neither U4 nor U6 from extracts prepared from recessive suppressors containing the snr6-A91G allele (lane 4) or the prp24-2 allele (lane $5)$ at $2.0 \mathrm{~m}$ salt or at any salt concentration we tested $(250$ $\mathrm{mm}$ to $2.0 \mathrm{M}$; data not shown). Although it appears that the binding of PRP24 to U6 is blocked in these strains, our assay cannot detect low-affinity binding because we cannot measure PRP24/U6 binding in wild-type strains at salt concentrations below $500 \mathrm{~mm} \mathrm{NaCl}$. Thus, these results suggest that the recessive suppressor mutations in SNR6 and PRP24 either disrupt or destabilize the association of PRP24 with the U6 snRNA.

PRP24 is associated with free U6 snRNP, not U4/U6 snRNP or U4/U5/U6 snRNP in wild-type extracts

In yeast, $\mathrm{U} 6$ is present in 5- to 10 -fold excess over $\mathrm{U} 4$ (D.A. Brow and C. Guthrie, unpubl.). U6 not associated with U4 migrates on gradients as a U6 snRNP (Hamm and Mattaj 1989; Bordonné et al. 1990). Gradient sedimentation of splicing extracts also resolves two other particles containing U6: U4/U6 and U4/U5/U6 (Black and Pinto 1989; Bordonné et al. 1990). Native gel electrophoresis (Konarska and Sharp 1987) and immunoprecipitation experiments (Bordonné et al. 1990) have demonstrated that the particles separated on glycerol gradients represent bona fide associations and not fortuitous comigrations. To determine whether PRP24 is associated with all U6-containing complexes or with specific U6-containing complexes, we fractionated wild-type yeast splicing extract on glycerol gradients, immunoprecipitated PRP24 from gradient fractions, and analyzed the coprecipitated RNA on Northern blots. A Northern blot of RNA isolated from gradient fractions showed that the gradient separated U4/U5/U6 (fractions 29-25), U4/ U6 (fractions 19-15), and free U6 snRNP (fractions 13-9) (Fig. 7A). Anti-PRP24 antiserum immunoprecipitated U6 only from the region of the gradient containing free U6 snRNP (fractions 14-10) (Fig. 7B). We think it is unlikely that PRP24 is inaccessible for the binding of antiPRP24 antibodies in the larger particles because the immunoprecipitation experiments were performed under conditions (750 $\mathrm{mm} \mathrm{NaCl}$ ) that disrupt the HeLa U4/U6 and U4/U5/U6 particles in vitro (R. Lührmann, pers. comm.). These observations suggest that PRP24 is associated specifically with free U6 snRNP in wild-type extracts. However, we cannot rule out the possibility that PRP24 also binds the U4/U6 helix, but it dissociates under the conditions necessary for immunoprecipitation.

We repeated these experiments with extract prepared from the snr14-G14C strain. The Northern blot of RNA isolated from the gradient fractions showed that the extracts prepared from the snr14-G14C strain contain significantly more U4/U6 snRNP (fractions 19-13) and significantly less free U6 snRNP (fractions 11-9) than the wild-type extracts (Fig. 7C). However, Northern blot analysis also showed that total RNA from this extract contained approximately fivefold more U4 than extracts prepared from the wild-type strain (data not shown). Thus, it appears that the excess U4 present in the snr14G14C strain can sequester the excess U6 normally found in wild-type strains into a U4/U6 snRNP. Anti-PRP24 antiserum immunoprecipitated $\mathrm{U} 4$ and $\mathrm{U} 6$ from the region of the gradient containing the U4/U6 snRNP (fractions 18-14) and free U6 snRNP (fractions 12-10). Thus, in contrast to wild-type strains, the snr14-G14C strain contains a U4/U6 snRNP population that is tightly associated with PRP24.

\section{Discussion}

Base-pairing, but not specific sequences, is required at two positions in U4/U6 stem II

We proposed previously that $\mathrm{U} 4$ and $\mathrm{U} 6$ are tightly associated via an extensive base-pairing interaction composed of two intermolecular helices, stem I and stem II (Brow and Guthrie 1988). The stem I interaction was 


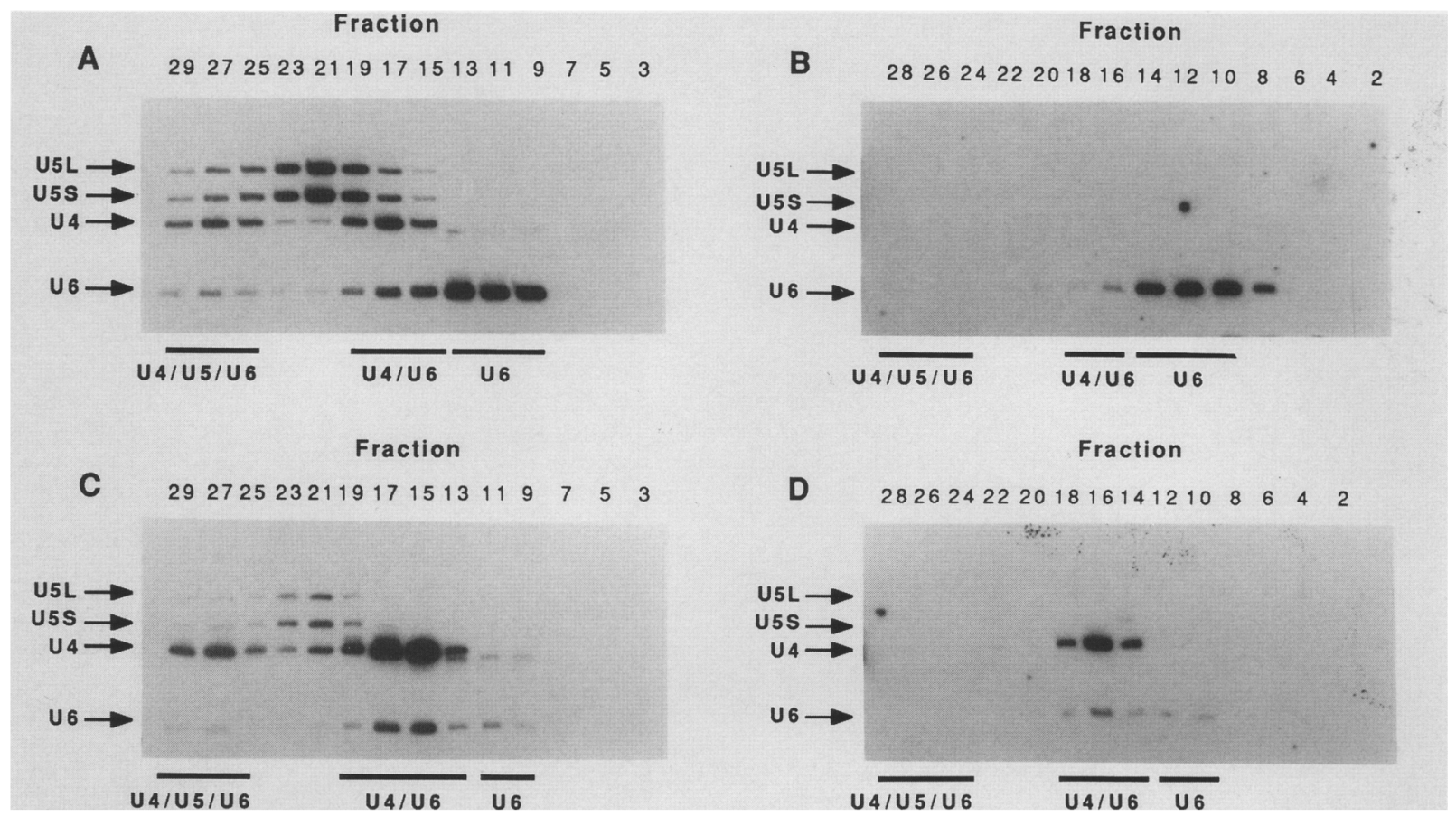

Figure 7. Immunoprecipitation of snRNPs with anti-PRP24 antiserum. Splicing extract prepared from a wild-type strain (MATa trp1 his3 ura3 ade2 lys2 snr14::TRP1 pUN90-SNR14) $(A$ and $B)$ or the snr14-G14C mutant (MATa trp1 his3 ura3 ade2 lys2 snr14::TRP1 pUN90-snr14-G14C) $(C$ and $D)$ was fractionated on a $10-30 \%$ glycerol gradient. RNA was recovered from odd-numbered fractions, electrophoresed on a $6 \%$ polyacrylamide denaturing gel, transferred to a nylon membrane, and probed with ${ }^{32} \mathrm{P}-1$ labeled oligonucleotides specific for U4, U5, and U6 ( $A$ and $C)$. Even-numbered fractions were incubated with anti-PRP24 antiserum at $750 \mathrm{mM} \mathrm{NaCl}$. RNA recovered from the immune complexes was analyzed as described above $(B$ and $D)$. The top of the gradient is at the right. The position of the bands corresponding to U4, U5, and U6 are indicated with arrows. The fraction numbers are indicated at the top, and the position of the different snRNPs are shown at the bottom.

previously established by psoralen cross-linking (Rinke et al. 1985). We have now provided genetic evidence for the existence of stem II. A U4 point mutation, snr14G14C, which is predicted to disrupt base-pairing in stem II of the interaction domain, dramatically destabilizes the U4/U6 complex in an in vitro assay, lowering the $T_{\mathrm{m}}$ from $53^{\circ} \mathrm{C}$ to $37^{\circ} \mathrm{C}$. This mutation and several nearby mutations in $U 4$ (positions $14,13,10$, and 9) cause a recessive, cold-sensitive lethal phenotype in vivo. Wildtype growth of strains carrying $\mathrm{U} 4$ mutations at positions 9 and 14 in stem II is restored by introducing U6 genes containing mutations predicted to restore basepairing with the U4 snRNA. This suppression is allelespecific because U6 genes containing noncompensatory mutations had no effect. These results demonstrate that a stable base-pairing interaction between $\mathrm{U} 4$ and $\mathrm{U} 6$ is essential for growth at low temperature.

\section{A suppressor of the base-pairing defect encodes a U6-binding protein}

We took advantage of the conditional lethal phenotype of the U4 mutations to understand the consequences of destabilizing the U4/U6 base-pairing interaction. We reasoned that destabilization of this complex might lead to the hyperstabilization of a competing interaction. In principle, the cold-sensitive phenotype could then be suppressed either by increasing the stability of the mutant U4/U6 complex or by decreasing the strength of the alternative interaction. We isolated spontaneous coldinsensitive suppressors of the $G \rightarrow C$ mutation in $U 4$ (snr14-G14C), which fell into three classes: (1) a dominant mutation in the U6 gene, SNR6, which restores U4/U6 base-pairing and U4/U6 complex stability; (2) recessive mutations in $S N R 6$, which are found in two regions outside the interaction domain and do not restabilize the U4/U6 complex; and (3) recessive mutations in PRP24. PRP24 was initially identified in a screen for temperature-sensitive lethal mutations that block premRNA splicing (Vijayraghavan et al. 1989). The prp24-1 mutant accumulates pre-mRNA at the nonpermissive temperature, suggesting that PRP24 acts prior to the first covalent modification in the splicing reaction.

We cloned and partially sequenced the PRP24 gene and noted sequence motifs characteristic of RNA-binding proteins of the RNP-consensus family. The gene was independently cloned by Mahshid Company and John Abelson, who provided us with the complete sequence. Upon examination, we identified three regions homologous to the RNP-consensus domain. This $\sim 80$-aminoacid motif is shared among a number of proteins that bind RNA, including polyadenylate-binding protein, het- 
erogeneous nuclear RNP (hnRNP) proteins, and proteins associated with specific U snRNPs (for review, see Bandziulis et al. 1989). We used immunoprecipitation experiments to show that PRP24 is tightly associated with the U6 snRNA in wild-type extracts. PRP24 remains bound to $\mathrm{U} 6$ at salt concentrations as high as $2 \mathrm{M} \mathrm{NaCl}$. For comparison, yeast poly(A)-binding protein binds poly(A) in vitro up to $1 \mathrm{M} \mathrm{NaCl}$, and hnRNP Al binds poly(U) in vitro up to $0.5 \mathrm{M} \mathrm{NaCl}$ (Swanson and Dreyfuss 1988). Although these experiments do not prove that PRP24 interacts directly with the RNA, analysis of the recessive suppressors demonstrated that the association of PRP24 with U6 is weakened by either single-base changes in U6 or by single-amino-acid changes in regions of PRP24 corresponding to the RNP 2 and RNP 1 motifs of the carboxy-terminal RNP-consensus domain. RNP 2 and RNP 1 are the two most highly conserved elements within the RNP-consensus domain and are essential for RNA binding in vitro. UV cross-linking experiments have shown that residues of RNP 2 and RNP 1 in hnRNP Al directly contact the bound nucleic acid (Merrill et al. 1988). Furthermore, mutations in RNP 2 and RNP 1 in the U1A protein block binding to Ul snRNA in vitro (Scherly et al. 1989). Together, these results suggest that PRP24 directly binds the U6 snRNA and that the regions of PRP24 and U6 defined by the recessive suppressor mutations may be good candidates for binding sites.

\section{A complex containing PRP24, U4, and U6} accumulates when the U4/U6 interaction is destabilized

U6 can be found in three particles: free U6, U4/U6, and U4/U5/U6. The formation of the U4/U5/U6 snRNP from the U4/U6 and U5 snRNPs appears to be an obligate step in vivo (Bordonné et al. 1990). This multisnRNP may function to deliver the U4, U5, and U6 snRNAs to the spliceosome (Konarska and Sharp 1987). The function of the free U6 snRNP is not known. Free U6 snRNP probably acts as a pool of U6 for the assembly of the U4/U6 and U4/U5/U6 snRNPs although it is also possible that free U6 snRNP represents a distinct population of U6 not normally recruited for multi-snRNP assembly.

In wild-type extracts, PRP24 is tightly associated with U6 in fractions enriched for the free U6 snRNP but is not detectable in fractions enriched for the U4/U6 snRNP or the U4/U5/U6 snRNP. Our experiments cannot distinguish whether PRP24 is a component of the entire free U6 snRNP population or whether PRP24 is associated with a specific subset of the free U6 snRNP. In contrast, both U4 and U6 are tightly associated with PRP24 in a strain containing the snr14-G14C mutation, which destabilizes the U4/U6 base-pairing interaction. Because $\mathrm{U} 4$ is overproduced approximately fivefold in the snr14G14C mutant, the levels of U4 and U6 are comparable to one another in this strain. Glycerol gradient fractionation of extracts prepared from the snr14-G14C strain showed that most of the U6 is found in a particle that migrates as a U4/U6 snRNP. However, unlike the U4/
U6 snRNP present in the wild-type strain, at least a fraction of the U4/U6 snRNP found in the snr14-G14C mutant contains PRP24. These results suggest that PRP24, $\mathrm{U} 4$, and U6 can form a stable complex in the snr14G14C mutant. The accumulation of the PRP24/U4/U6 complex is apparently caused by destabilizing the U4/U6 interaction, since PRP24 bound only U6 in a dominant suppressor strain containing the snr14-G14C mutation and the $\mathrm{U} 6$ mutation that restores U4/U6 base pairing.

\section{A model for PRP24-mediated suppression}

We have shown that destabilizing the U4/U6 base-pairing interaction leads to a cold-sensitive phenotype and the accumulation of a novel complex containing PRP24, U4, and U6. In the simplest view, the inability to grow at low temperature is causally related to the accumulation of the PRP24/U4/U6 complex. This is consistent with the idea that cold sensitivity is due to the hyperstabilization of a complex. We have not yet tested whether the accumulation of the PRP24/U4/U6 complex is exacerbated in extracts prepared from snr14-G14C cells shifted to $18^{\circ} \mathrm{C}$; however, this kind of experiment is complicated by the fact that splicing extracts are prepared at temperatures well below the permissive temperature for the growth of this mutant strain. If the accumulation of the PRP24/U4/U6 complex causes the cold-sensitive phenotype, then mutations that reduce the levels of this complex would be expected to act as suppressors. Indeed, the two classes of recessive suppressors appear to inhibit the binding of PRP24 to U6. This leads us to propose that a reaction exists that interconverts the PRP24/U4/U6 complex and the U4/U6 complex. Mutations that destabilize the U4/U6 complex drive the reaction toward the formation of the PRP24/U4/U6 complex. The recessive suppressors compensate by reducing the affinity of PRP24 for U6, either by partially inactivating the binding activity of the protein or the binding site(s) on the RNA. Although we cannot yet rule out the possibility that the PRP24/U4/U6 complex is aberrant and unique to the snr14-G14C mutant, we favor the interpretation that the PRP24/U4/U6 complex is a normal intermediate in the U4/U6 cycle.

A model that integrates this reaction into the spliceosome assembly pathway is outlined in Figure 8. According to this model, the PRP24/U4/U6 complex is normally a transient intermediate in the annealing of the U4 and U6 snRNAs. After PRP24/U6 binds U4, PRP24 dissociates from the PRP24/U4/U6 complex concomitant

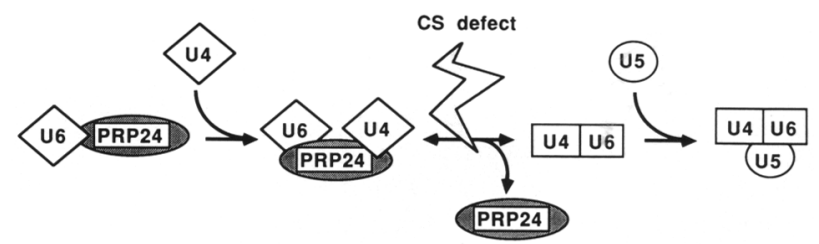

Figure 8. Model outlining the potential function of PRP24 in the U4/U6 cycle. 
with the formation of the U4/U6 helix. This reaction may be involved in the initial assembly of the U4/U6 snRNP during snRNP biogenesis and/or in the reassembly of the U4/U6 complex after the U4/U6 interaction is disrupted in the formation of the active spliceosome. In either case, the accumulation of the PRP24/U4/U6 complex in the cold-sensitive mutants would act to sequester $\mathrm{U} 4$ and $\mathrm{U} 6$ so that the U4/U6 complex cannot efficiently form for the next round of splicing. This model is consistent with our data showing that mutations that destabilize the U4/U6 base-pairing interaction lead to the accumulation of the PRP24/U4/U6 complex. The recessive suppressor mutations destabilize the binding of PRP24 to U6 and thus promote the release of PRP24 from the PRP24/U4/U6 complex to allow the formation of the base-paired U4/U6 complex. This model predicts that the U4/U6 base-pairing interaction is partially or completely disrupted in the PRP24/U4/U6 complex. Intriguingly, Brow and Guthrie (1988) found two forms of the $\mathrm{U} 4 / \mathrm{U} 6$ complex in HeLa cell nuclear extracts: a high- $T_{\mathrm{m}}$ form, with a melting temperature similar to that of the yeast U4/U6 complex, and a low- $T_{\mathrm{m}}$ form. It is possible that the PRP24/U4/U6 complex we identified in the U4 mutant strain may represent the low $-T_{\mathrm{m}}$ form of the U4/ U6 complex identified previously in human cells. Biochemical analysis of the U4/U6 interaction in the PRP24/U4/U6 complex is currently under way to test this hypothesis.

Although our data indicate a role for PRP24 in the annealing of U4 and U6, PRP24 may play additional roles in the U4/U6 cycle. For example, once the U4/U6 basepairing interaction is disrupted in the spliceosome, the tight binding of PRP24 to U6 could act to stabilize the unwound form. Interestingly, another member of the RNP-consensus family, hnRNP Al, can either promote the renaturation of complementary single-stranded nucleic acids (Pontius and Berg 1990) or inhibit annealing by binding preferentially to single strands (Kumar et al. 1986), depending on the assay conditions. In support of this hypothesis, we have recently found that a temperature-sensitive mutation in PRP24 is inviable in combination with a cold-sensitive mutation in PRP28, which encodes a putative ATP-dependent RNA helicase (Strauss and Guthrie 1991). This synthetic lethality suggests that PRP24 and PRP28 act at a similar point in the splicing pathway. Future experiments to determine whether PRP24 is associated with specific splicing complexes will test the idea that PRP24 is involved in two distinct but related steps of the U4/U6 cycle.

\section{Materials and methods}

Site-directed mutagenesis of SNR14 and SNR6

A $0.55-\mathrm{kb}$ EcoRV-EcoRI fragment carrying the SNR14 gene ( $\mathrm{Si}$ liciano et al. 1987) was cloned into Bluescript (+) (Stratagene). The plasmid pEP6 contains a 1.8-kb EcoRI-Pst fragment carrying the SNR6 gene in pUC118 (Brow and Guthrie 1988). Preparation of single-stranded DNA from $d u t^{-} u n g^{-}$cells carrying these plasmids and oligonucleotide-directed mutagenesis were performed, as described (Kunkel et al. 1987; McClary et al.
1989). EcoRI-BamHI fragments carrying the $s n r 14$ genes were subcloned into pUN90 (CEN, HIS3) (Elledge and Davis 1988). EcoRI-HpaI fragments carrying the snr6 genes were subcloned into YCp50 (CEN, URA3) (Parent et al. 1985). The sequence of each construct was confirmed by dideoxynucleotide sequencing using Sequenase (U.S. Biochemicals).

\section{Yeast strains and genetic methods}

All strains used in this study are derived from Saccharomyces cerevisiae strain YKS2 (MATa trp1 his3 ura3 ade2 lys2 snr14::TRP1 YCp50-SNR14). YKS2 is a haploid strain carrying a deletion of the chromosomal copy of the SNR14 gene that is complemented by the wild-type SNR14 gene carried on YCp50 (CEN, URA3). The preparation of growth media and the techniques used for diploid construction, sporulation, and tetrad dissection have been described (Rose et al. 1989). Intact yeast cells were transformed using lithium acetate (Ito et al. 1983).

The snr14 mutant strains were generated using the plasmid shuffle technique (Boeke et al. 1987). The strain YKS2 was transformed with the plasmids carrying the snr14 genes. Transformants were selected on SD medium lacking histidine at $30^{\circ} \mathrm{C}$ and then plated onto SD medium containing $0.75 \mathrm{mg} / \mathrm{ml}$ of 5-fluoro-orotic acid (5-FOA) to select for cells that have lost the YCp50-SNR14 plasmid.

Two cold-sensitive haploid strains were used for reversion analysis. The construction of strain snr14-G14C (MATa trp1 his3 ura3 ade2 lys2 snr14::TRP1 pUN90-snr14-G14C) was described above. This strain was plated on SD medium lacking histidine and incubated at $18^{\circ} \mathrm{C}$ to select for spontaneous coldinsensitive revertants. Revertants arose at a frequency of $6 \times 10^{-8}$. The suppressor strains containing the $S N R 6-C 67 G$, snr6-T38C, snr6-A40G and snr6-C43G, and snr6-A91G mutations were isolated from this selection. The strain snr14-G14C YCp50-SNR6 was generated by transforming snr14-G14C with YCp50-SNR6, which contains the 1.8-kb EcoRI-PstI fragment carrying the wild-type SNR6 gene. This strain was plated on SD medium lacking histidine and uracil and incubated at $18^{\circ} \mathrm{C}$. Revertants arose at a frequency of $4 \times 10^{-8}$. Before further analysis, these revertants were plated on medium containing 0.75 $\mathrm{mg} / \mathrm{ml} 5$-FOA to select for cells that lost the YCp50-SNR6 plasmid. The suppressor strains containing the prp24-2, prp24-3, and prp24-4 mutations were isolated using this scheme. To test dominance or recessiveness, each revertant was crossed to the strain YKS3 (MATa trp1 his3 ura3 ade2 lys2 snr14::TRP1 YCp50-SNR14) and diploids were selected on SD medium lacking histidine and uracil at $30^{\circ} \mathrm{C}$. Diploids were plated on medium containing $0.75 \mathrm{mg} / \mathrm{ml} 5$-FOA to select for cells that lost the YCp50-SNR14 plasmid and then tested for their ability to grow at $18^{\circ} \mathrm{C}$. The Ura ${ }^{-}$diploids were sporulated and tetrads were dissected to analyze Mendelian segregation of the suppressor mutations and to isolate MATa and MATa suppressor strains for complementation analysis.

\section{Melting temperature determinations}

Melting temperature of the U4/U6 complex in deproteinized splicing extract fraction I (Cheng and Abelson 1986) was determined by the method of Brow and Guthrie (1988).

\section{Isolation and characterization of the snr6 alleles}

A yeast genomic library enriched for the U6 gene was prepared from genomic DNA isolated from the suppressor strain containing the snr6-A91G mutation (MATa trp1 his3 ura3 ade2 lys2 snr14::TRP1 pUN90-snr14-G14C snr14-A91G). Total geno- 
mic DNA was prepared as described (Denis and Young 1983) and digested with EcoRI. Fragments ranging from 3.7 to $2.3 \mathrm{~kb}$ were recovered from a $0.7 \%$ agarose gel, digested with PstI and ligated into the EcoRI and PstI sites of pUC118. Bacterial colonies transformed with the ligation mixture were plated and transferred onto nitrocellulose (Ish-Horowicz and Burke 1981). The filters were probed with U6-specific oligonucleotides endlabeled with $\left[\gamma^{32}\right.$ P $\mid$ ATP. Plasmid DNA isolated from two clones contained a $1.05-\mathrm{kb}$ EcoRI-ClaI fragment characteristic of SNR6. Dideoxynucleotide sequencing of these plasmids revealed a single mutation in the U6-coding region.

Total RNA was prepared from the suppressor strains containing the SNR6-C67G, snr6-T38C, snr6-A40G, and snr6-C43G mutations using the guanidium thiocyanate method (Wise et al. 1983). RNA sequencing was performed as described (Zaug et al. 1984 |, by reverse transcription from an end-labeled oligonucleotide primer complementary to nucleotides 96-112 of U6. Most of the U6 sequence (nucleotides 5-76) was determined for each snr6 allele, and a single-nucleotide change was found in each case.

\section{Isolation and characterization of the prp24 alleles}

The PRP24 gene was cloned on the basis of its ability to rescue the temperature-sensitive cold-resistant phenotype of the suppressor strain containing the prp24-4 mutation (MATa trp1 his3 ura3 ade2 lys2 snr14::TRP1 pUN90-snr14-G14C prp24-4). This strain was transformed with a yeast genomic library constructed in YCp50 (Rose 1987), and transformants were selected on SD medium lacking histidine and uracil at $37^{\circ} \mathrm{C}$. Two transformants were isolated that showed the temperature-resistant cold-sensitive phenotype characteristic of the prp24-4/PRP24 diploid. Each transformant reverted to the temperature-sensitive cold-resistant phenotype of the prp24-4 haploid strain when plated on medium containing 5-FOA. DNA isolated from these transformants was used to transform (Dower et al. 1988) E. coli strain MH5 to ampicillin resistance and uracil prototropy. Plasmid DNA isolated from these transformants conferred temperature resistance and cold sensitivity when transformed into the suppressor strain containing the prp24-4 mutation. One of these plasmids was digested with $X b a \mathrm{I}$, and a $3.5-\mathrm{kb}$ fragment was gel-purified and ligated into pUN50 (CEN, URA3) (Elledge and Davis 1988). This subclone (YCpXba) was sufficient to complement the temperature-sensitive and cold-resistant phenotype of the suppressor strain containing the prp24-4 mutation. The prp24 suppressor alleles were isolated from the suppressor strains containing the prp24-2, prp24-3, and prp24-4 mutations by the gap repair method (Orr-Weaver et al. 1981) using the YCpXba plasmid linearized with ClaI.

\section{Production of anti-PRP24 antiserum and immunoprecipitation experiments}

YCpXba was digested with $\mathrm{HaeII}$ and $\mathrm{XbaI}$, and a 1.59-kb fragment that encodes the carboxy-terminal 378 amino acids of PRP24 was gel-purified and ligated into the SmaI and XbaI sites of the trpE fusion vector pATH2 (Spindler et al. 1984). Plasmid DNA was isolated from $E$. coli strain DG-98 and then used to transform the protease-deficient $E$. coli strain CAG456 to ampillicin resistance at $30^{\circ} \mathrm{C}$. The induction of the gene fusion with indoleacrylic acid and the preparation of insoluble fraction of $E$. coli lysate have been described (Snyder et al. 1989). The trpE-PRP24 fusion protein was purified from the insoluble fractions by electroelution from gel slices (Hunkapiller et al. 1983).

The purified trpE-PRP24 fusion protein $(500 \mu \mathrm{g})$ was injected subcutaneously into New Zealand white rabbits (Berkeley An- tibody Company, Richmond, CA). Additional protein $(250 \mu \mathrm{g})$ was injected at 3-week intervals. The antiserum used in these studies was obtained from a single rabbit bled 10 days after the third injection. Antibodies were affinity-purified using the trpE-PRP24 fusion protein as described (Smith and Fisher 1984).

Anti-PRP24 antiserum $(10 \mu l)$ was coupled to protein-A/Sepharose (Pharmacia) and washed three times with Ipp500 buffer (Hamm et al. 1987) and once with Ipp buffer (10 mM Tris-Cl at $\mathrm{pH} 8.0,0.1 \%$ NP- $40,0.1 \%$ sodium azide) containing various concentrations of $\mathrm{NaCl}$ (indicated in the figure legends). Twenty-five microliters of yeast splicing extract (Lin et al. 1985) or $400 \mu \mathrm{l}$ of gradient fraction and $400 \mu \mathrm{l}$ Ipp buffer were added to the washed beads and incubated for $1 \mathrm{hr}$ at $4^{\circ} \mathrm{C}$. The beads were washed three times with Ipp buffer at the salt concentration used in the incubation with antiserum. The RNA was extracted with phenol-chloroform, precipitated with three volumes of ethanol, and analyzed by Northern blot analysis as described previously (Bordonné et al. 1990).

\section{Glycerol gradient fractionation}

Yeast splicing extract (1.0 mg protein) was incubated for $30 \mathrm{~min}$ at $25^{\circ} \mathrm{C}$ in $60 \mu \mathrm{M}$ potassium phosphate (pH 7.0), $2.5 \mathrm{~mm} \mathrm{MgCl}_{2}$, and $2 \mathrm{mM}$ ATP. The mixture was diluted with buffer A $150 \mathrm{~mm}$ Tris- $\mathrm{Cl}$ at $\mathrm{pH} 7.4,25 \mathrm{~mm} \mathrm{NaCl}, 5 \mathrm{~mm} \mathrm{MgCl}_{2}$ ) and layered onto $10-30 \%$ glycerol gradients. The preparation and analysis of the glycerol gradients have been described (Bordonné et al. 1990).

\section{Acknowledgments}

We gratefully acknowledge Mahshid Company and John Abelson for sharing the PRP24 sequence prior to publication. We thank David Brow, Hiten Madhani, Pat O'Farrell, and Paul Schedl for the many helpful discussions, and Ira Herskowitz, John Abelson, and members of the Guthrie laboratory for critical reading of the manuscript. Finally, we extend special thanks to Lucita Esperas who provided excellent technical assistance. This work was supported by a National Institutes of Health grant (GM21119) to C.G. and an American Cancer Society postdoctoral fellowship (PF-3009) awarded to K.W.S.

The publication costs of this article were defrayed in part by payment of page charges. This article must therefore be hereby marked "advertisement" in accordance with 18 USC section 1734 solely to indicate this fact.

\section{References}

Bandziulis, R.J., M.S. Swanson, and G. Dreyfuss. 1989. RNAbinding proteins as developmental regulators. Genes \& Dev. 3: $431-437$.

Bindereif, A. and M.R. Green. 1987. An ordered pathway of snRNP binding during mammalian pre-mRNA splicing complex assembly. $E M B O$ J. 6: 2415-2424.

Bindereif, A., T. Wolff, and M.R. Green. 1990. Discrete domains of human U6 snRNA required for the assembly of U4/U6 snRNP and splicing complexes. EMBO J. 9: 251-255.

Black, D.L. and A.L. Pinto. 1989. U5 small nuclear ribonucleoprotein: RNA structure analysis and ATP-dependent interaction with U4/U6. Mol. Cell. Biol. 9: 3350-3359.

Black, D.L., B. Chabot, and J.A. Steitz. 1985. U2 as well as U1 small nuclear ribonucleoproteins are involved in premessenger RNA splicing. Cell 42: 737-750.

Boeke, J.D., J. Truehart, G. Natsoulis, and G.R. Fink. 1987. 5Fluoroorotic acid as a selective agent in yeast molecular genetics. Methods Enzymol. 154: 164-175. 
Bordonné, R., J. Banroques, J. Abelson, and C. Guthrie. 1990. Domains of yeast U4 spliceosomal RNA required for PRP4 protein binding, snRNP-snRNP interactions, and pre-mRNA splicing in vivo. Genes \& Dev. 4: 1185-1196.

Bringmann, P., B. Appel, J. Rinke, R. Reuter, H. Theissen, and R. Lührmann. 1984. Evidence of the existence of snRNAs U4 and $\mathrm{U} 6$ in a single ribonucleoprotein complex and for their association by intermolecular base pairing. EMBO $J$. 3: $1357-1363$.

Brow, D.A. and C. Guthrie. 1988. Spliceosomal RNA U6 is remarkably conserved from yeast to mammals. Nature 334: 213-218.

. 1989. Splicing a spliceosomal RNA. Nature 337: 14-15.

Cheng, S.C. and J. Abelson. 1987. Spliceosome assembly in yeast. Genes \& Dev. 1: 1014-1027.

Denis, C.L. and E.T. Young. 1983. Isolation and characterization of the positive regulatory gene $A D R 1$ from Saccharomyces cerevisiae. Mol. Cell. Biol. 3: 360-370.

Dower, W.J., J.F. Miller, and C.W. Ragsdale. 1988. High efficiency transformation of $E$. coli by high voltage electroporation. Nucleic Acids Res. 16: 6127-6145.

Elledge, S.J. and R.W. Davis. 1988. A family of versatile centromeric vectors for use in the sectoring-shuffle mutagenesis assay in Saccharomyces cerevisiae. Gene 70: 303-312.

Grange, T., C. Martins de Sa, J. Oddos, and R. Pictet. 1987. Human mRNA polyadenylate binding protein: Evolutionary conservation of a nucleic acid binding motif. Nucleic Acids Res. 15: 4771-4787.

Guthrie, C. and B. Patterson. 1988. Spliceosomal snRNAs. Annu. Rev. Genet. 23: 387-419.

Hamm, J. and I.W. Mattaj. 1989. An abundant U6 snRNP found in germ cells and embryos of Xenopus laevis. EMBO $\mathrm{J}$. 8: $4179-4187$.

Hamm, J., M. Kazmaier, and I.W. Mattaj. 1987. In vitro assembly of U1 snRNPs. EMBO /. 6: 3479-3485.

Hartwell, L.H. 1967. Macromolecule synthesis in temperaturesensitive mutants of yeast. J. Bacteriol. 93: 1662-1670.

Hashimoto, C. and J.A. Steitz. 1984. U4 and U6 RNAs coexist in a single small nuclear ribonucleoprotein particle. Nucleic Acids Res. 12: 3283-3293.

Haynes, S.R., M.L. Rebbert, B.A. Mozer, F. Forquignon, and I.B. Dawid. 1987. pen repeat sequences are GGN clusters and encode a glycine-rich domain in a Drosophila cDNA homologous to the rat helix destabilizing protein. Proc. Natl. Acad. Sci. 84: 1819-1823.

Hunkapillar, M.W., E. Lujan, F. Ostrander, and L.E. Hood. 1983. Isolation of microgram quantities of proteins from polyacrylamide gels for amino acid sequence analysis. Methods Enzymol. 91: 227-236.

Ish-Horowicz, D. and J.F. Burke. 1981. Rapid and efficient cosmid cloning. Nucleic Acids Res. 9: 2989-2998.

Ito, H., Y. Fukuda, K. Murata, and A. Kimura. 1983. Transformation of intact yeast cells treated with alkali cations. $J$. Bacteriol. 153: 163-168.

Konarska, M.M. and P.A. Sharp. 1987. Interactions between small nuclear ribonucleoprotein particles in formation of spliceosomes. Cell 49: 763-774.

Kumar, A., K.R. Williams, and W. Szer. 1986. Purification and domain structure of core hnRNP proteins $A 1$ and $A 2$ and their relationship to single-stranded DNA-binding proteins. J. Biol. Chem. 261: 11266-11273.

Kunkel, T.A., J.D. Roberts, and R.A. Zakour. 1987. Rapid and efficient site-specific mutagenesis without phenotypic selection. Methods Enzymol. 154: 367-382.

Lamond, A.I., M.M. Konarska, P.J. Grabowski, and P.A. Sharp. 1988. Spliceosome assembly involves the binding and re- lease of U4 small nuclear ribonucleoprotein. Proc. Natl. Acad. Sci. 85: 411-415.

Lin, R.J., A.J. Newman, S.C. Cheng, and J. Abelson. 1985. Yeast mRNA splicing in vitro. I. Biol. Chem. 260: 14780-14792.

Lührmann, R. 1988. snRNP proteins. In Structure and function of major and minor small nuclear ribonucleoprotein particles (ed. M.L. Birnstiel), pp. 71-99. Springer Verlag, Heidelberg/New York/London/Paris/Tokyo.

McClary, J.A., F. Witney, and J. Geisselsoder. 1989. Efficient site-directed in vitro mutagenesis using phagemid vectors. Biotechniques 3: 282-289.

Merrill, B.M., K.L. Stone, F. Cobianchi, S.H. Wilson, and K.R. Williams. 1988. Phenylalanines that are conserved among several RNA-binding proteins form part of a nucleic acidbinding pocket in the $\mathrm{Al}$ heterogeneous nuclear ribonucleoprotein. J. Biol. Chem. 263: 3307-3313.

Mount, S.M., I. Petterson, M. Hinterberger, A. Karmas, and J.A. Steitz. 1983. The Ul small nuclear RNA-protein complex selectively binds a $5^{\prime}$ splice site in vitro. Cell 33: 509-518.

Orr-Weaver, T.L., J.W. Szostak, and R.J. Rothstein. 1981. Yeast transformation: A model system for the study of recombination. Proc. Natl. Acad. Sci. 78: 6354-6358.

Parent, S.A., C.M. Fenimore, and K.A. Bostain. 1985. Vector systems for the expression, analysis and cloning of DNA sequences in S. cerevisiae. Yeast 1: 83-138.

Pikielny, C.W., B.C. Rymond, and M. Roshbash. 1986. Electrophoresis of ribonucleoproteins reveals an ordered assembly pathway of yeast splicing complexes. Nature 324: 341-345.

Pikielny, C.W., A. Bindereif, and M.R. Green. 1989. In vitro reconstitution of snRNPs: A reconstituted U4/U6 snRNP participates in splicing complex formation. Genes \& Dev. 3: $479-487$.

Pontius, B.W. and P. Berg. 1990. Renaturation of complementary DNA strands mediated by purified mammalian heterogeneous nuclear ribonucleoprotein Al protein: Implications for a mechanism for rapid molecular assembly. Proc. Natl. Acad. Sci. 87: 8403-8407.

Query, C.C., R.C. Bentley, and J.D. Keene. 1989. A common RNA recognition motif identified within a defined UI RNA binding domain of the 70K Ul snRNP protein. Cell 57: 89101.

Rinke, J., B. Appel, M. Digweed, and R. Lührmann. 1985. Localization of a base-paired interaction between small nuclear RNAs U4 and U6 in intact U4/U6 ribonucleoprotein particles by psoralen cross-linking. J. Mol. Biol. 185: 721-731.

Robinow, S., A.R. Campos, K.-M. Yao, and K. White. 1988. The elav gene product of Drosophila, required in neurons, has three RNP consensus motifs. Science 242: 1570-1572.

Rose, M.D. 1987. Isolation of genes by complementation in yeast. Methods Enzymol. 152: 481-502.

Rose, M.D., F. Winston, and P. Heiter. 1989. Methods in yeast genetics. Cold Spring Harbor Laboratory Press, Cold Spring Harbor, New York.

Schena, M., D. Picard, and K.R. Yamamoto. 1991. Vectors for constitutive and inducible gene expression in yeast. Methods Enzymol. 194: 389-398.

Scherly, D., W. Boelens, W.J. van Venrooij, N.A. Dathan, J. Hamm, and I.W. Mattaj. 1989. Identification of the RNA binding segment of human U1A protein and definition of its binding site on U1 snRNA. EMBO I. 8: 4163-4170.

Sharp, P.A. 1987. Splicing messenger RNA precursors. Science 235: 766-771.

Siliciano, P.G., D.A. Brow, H. Roiha, and C. Guthrie. 1987. An essential snRNA from $S$. cerevisiae has properties predicted for U4, including interaction with U6-like snRNA. Cell 50: $585-592$. 
Sillekens, P.T.G., W.J. Habets, R.P. Beijer, and W.J. Venrooij. 1987. cDNA cloning of the human U1 snRNA-associated A protein: Extensive homology between U1 and U2 snRNPspecific proteins. EMBO I. 6: 3841-3848.

Smith, D.E. and P.A. Fisher. 1984. Identification, developmental regulation, and response to heat shock of two antigenically related forms of a major nuclear envelope protein in Drosophila embryos: Application of an improved method for affinity purification of antibodies using polypeptides immobilized on nitrocellulose blots. J. Cell Biol. 99: 20-28.

Snyder, M. 1989. The SPA2 protein of yeast localizes to sites of cell growth. J. Cell Biol. 108: 1419-1429.

Spindler, K.R., D.S.E. Rosser, and A.J. Berk. 1984. Analysis of adenovirus transforming proteins from early regions $1 \mathrm{~A}$ and $1 B$ with antisera to inducible fusion antigens produced in Escherichia coli. J. Virol. 49: 132-141.

Strauss, E.J. and C. Guthrie. 1991. A cold-sensitive mRNA splicing mutant is a member of the RNA helicase gene family. Genes \& Dev. 5: 629-641.

Swanson, M.S. and G. Dreyfuss. 1988. Classification and purification of proteins of heterogeneous nuclear ribonucleoprotein particles by RNA-binding specificities. Mol. Cell. Biol. 8: 2237-2241.

Theissen, H., M. Etzerodt, R. Reuter, C. Schneider, F. Lottspeich, P. Argos, R. Lührmann, and L. Philipson. 1986. Cloning of the human cDNA for the U1 RNA-associated $70 \mathrm{~K}$ protein. EMBO J. 5: 3209-3217.

Vankan, P., C. McGuigan, and I.W. Mattaj. 1990. Domains of U4 and U6 snRNAs required for snRNP assembly and splicing complementation in Xenopus oocytes. EMBO I. 9: 33973404.

Vijayraghavan, U., M. Company, and J. Abelson. 1989. Isolation and characterization of pre-mRNA splicing mutants of Saccharomyces cerevisiae. Genes \& Dev. 3: 1206-1216.

Wise, J.A., D. Tollervey, D. Maloney, H. Swerdlow, E.J. Dunn, and C. Guthrie. 1983. Yeast contains small nuclear RNAs encoded by single-copy genes. Cell 35: 743-751.

Zaug, A.J., J.R. Kent, and T.R. Cech. 1984. A labile phosphodiester bond at the ligation junction in a circular intervening sequence RNA. Science 224: 574-578. 


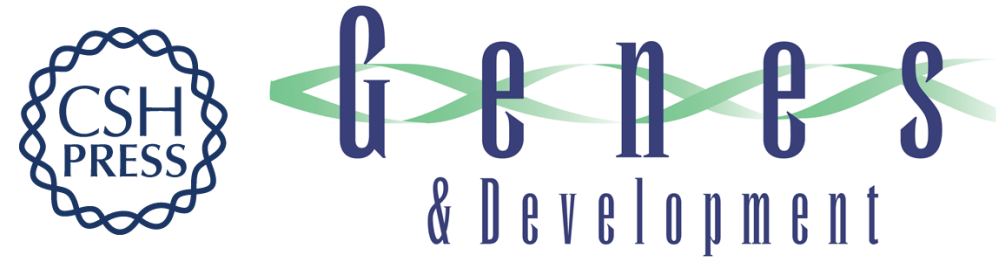

\section{Suppressors of a U4 snRNA mutation define a novel U6 snRNP protein with RNA-binding motifs.}

K W Shannon and C Guthrie

Genes Dev. 1991, 5:

Access the most recent version at doi:10.1101/gad.5.5.773

References This article cites 56 articles, 24 of which can be accessed free at:

http://genesdev.cshlp.org/content/5/5/773.full.html\#ref-list-1

License

Email Alerting

Service

Receive free email alerts when new articles cite this article - sign up in the box at the top right corner of the article or click here.

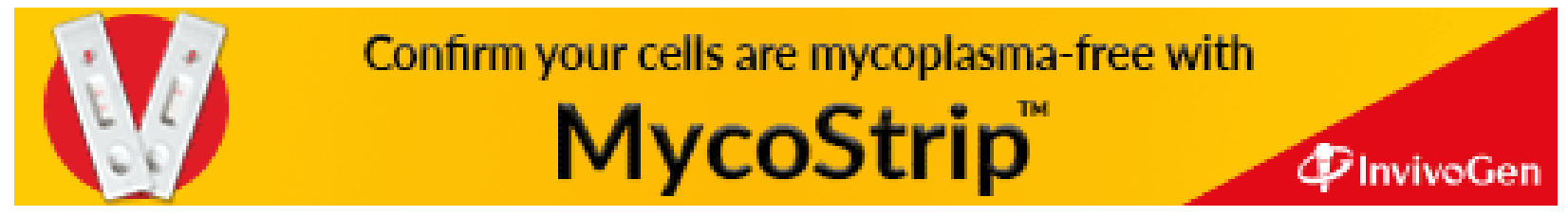

